P. D. O'SHEA, * C. CHEN,* W. CHEN, P. DAGNEAU, L. F. FREY, E. J. J. GRABOWSKi, K. M.

Practical Asymmetric Synthesis of a Potent PDE4 Inhibitor via Stereoselective Enolate Alkylation of a Chiral ArylHeteroaryl Secondary Tosylate

J. Org. Chem. 2005, 70, 3021-3030.

\title{
Asymmetric Synthesis of L-869,298, a Potent PDE4 Inhibitor
}

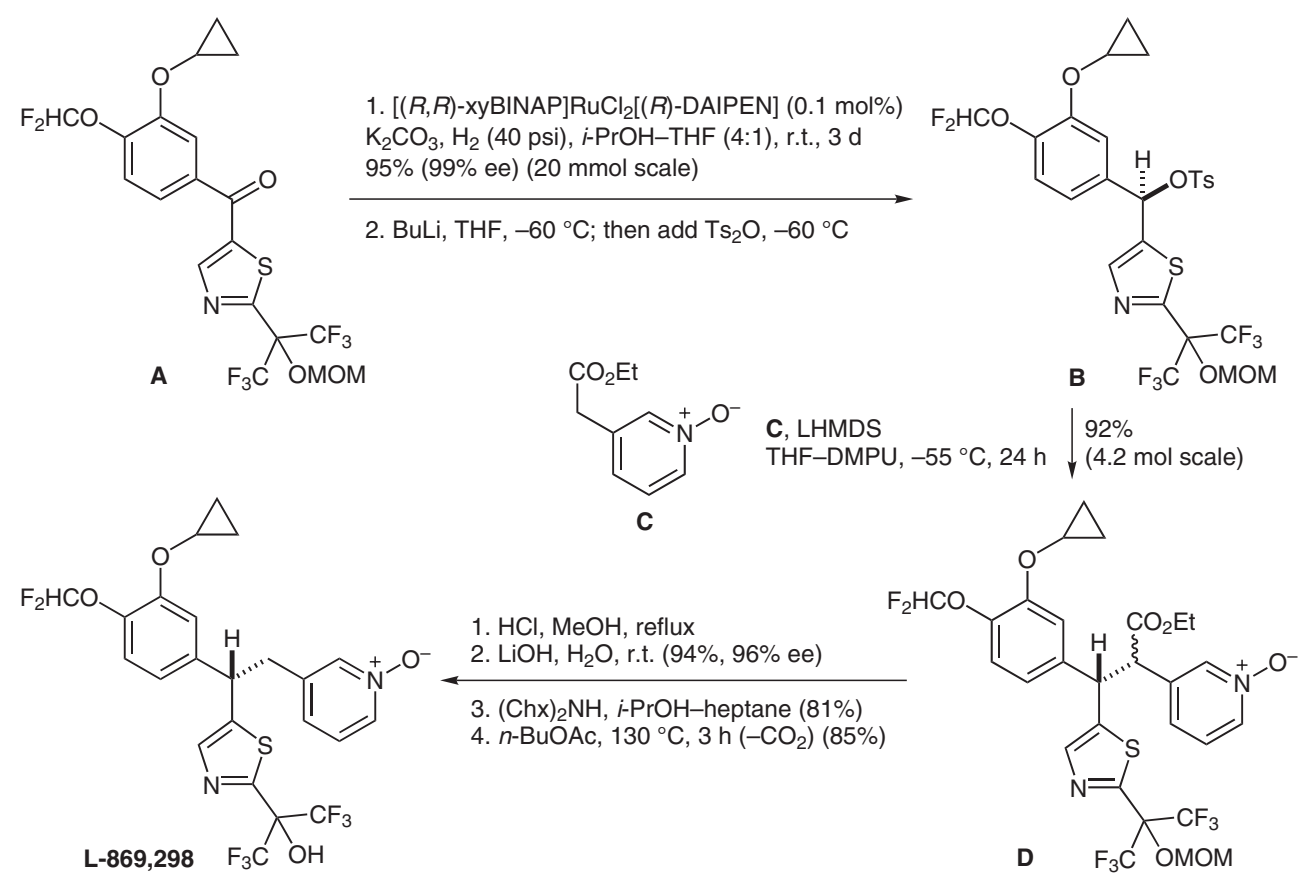

Significance: The target molecule inhibits phosphodiesterase-4 (PDE4), an enzyme that hydrolyzes cAMP. It is a potential drug for the treatment of asthma and chronic obstructive pulmonary disease.
Comment: Noyori asymmetric hydrogenation gave the most efficient reduction of $\mathbf{A}$. The unstable tosylate $\mathbf{B}$ underwent substitution with the lithium enolate of pyridine $\mathrm{N}$-oxide $\mathbf{C}$ to give $\mathbf{D}$ in $92 \%$ yield with no loss of enantiopurity. The cyclopropyl ether was synthesized on a $21.5 \mathrm{~mol}$ scale by reaction of a phenolic vinyl ether with $\mathrm{Et}_{2} \mathrm{Zn}$ and $\mathrm{CH}_{2} \mathrm{I}_{2}$. 